\title{
Aníbal Quijano y su tiempo ${ }^{1}$ $(1930-2018)$
}

Recibido: 05/03/2019

Aprobado: 10/05/2019

MANUEL VALLADARES QUIJANO

Universidad Nacional Mayor de San Marcos

manuelvalladaresq@gmail.com

\section{RESUMEN}

El artículo presenta un recorrido sobre la biografía personal, intelectual y política de Aníbal Quijano, desde sus orígenes en Áncash, su temprana juventud, formación académica y su compromiso con la militancia en la izquierda. Analiza sus propuestas más resaltantes, desde el marxismo, la teoría de la dependencia y la colonialidad. Rescata la coherencia de Quijano, dentro de su concepción ideológica y política hasta su prolífica producción sociológica, junto con sus aportes e investigaciones más resaltantes.

Palabras clave: Intelectual, revolución, política, investigación.

\section{Anibal Quijano and his time (1930-2018)}

\begin{abstract}
The article presents an overview on the personal, intellectual and political biography of Anibal Quijano. From his origins in Ancash, his early youth, his academic formation and his commitment to left-wing militancy. It examines his most outstanding proposals, from the Marxism, the theory of dependency and coloniality. It emphasizes Quijano's coherence, from his ideological and political conception to his prolific sociological production, along his more notable contributions and studies.
\end{abstract}

Keywords: Intellectual, revolution, politics, research.

1 El presente texto es una ampliación tanto cronológica como narrativa de una versión original titulada "Aníbal Quijano: orígenes de sus luchas contra el poder", publicado en la revista Investigaciones Sociales, 40 (diciembre 2018-abril 2019), de la Facultad de Ciencias Sociales de la Universidad Nacional Mayor de San Marcos. 
E n las páginas que siguen se hace referencia a ciertas etapas, fases o momentos de la trayectoria intelectual y vital de Aníbal Quijano, quien desde su temprana juventud fue haciendo suyo el pensamiento socialista revolucionario, anticapitalista y antiburgués, cuestión que, a su vez, fue convirtiéndose en una constante y en la columna vertebral de sus reflexiones, investigaciones, enseñanzas y debates. Se propone identificar algunos de los factores que probablemente jugaron un papel significativo en el proceso de su evolución ideológica y política.

\section{Nacer y crecer bajo el intenso azul del cielo serrano}

Aníbal Quijano Obregón nació el 17 de noviembre de 1930 en el distrito de Yanama, provincia de Yungay, departamento de Áncash, como consta en su partida de nacimiento expedida por la respectiva municipalidad distrital. Sus padres fueron Marcial Quijano Vega y Alfonsa Obregón Agama, ambos jóvenes veinteañeros, él maestro de escuela como "preceptor diplomado" y más tarde "normalista" y ella dedicada básicamente a las labores domésticas. Había que compartir responsabilidades en el cuidado del recién nacido y de sus dos hermanas mayores, aún niñas, que se llamaban Luzmila y Amelia. Los tres hijos crecieron en la casa familiar, bajo directa responsabilidad de sus padres y ante la sombra protectora del abuelo materno, don Liborio Obregón Sáenz, empeñado en su trabajo artesanal como tejedor de alfombras, ocupando con frecuencia parte del amplio corredor de la casa, aunque preferentemente dedicado a sus principales tareas como eran la crianza de animales y las actividades agrícolas en sus chacras en los diferentes pisos ecológicos de la zona. En la casa vecina, apenas separada por un huerto, vivían los abuelos paternos Agustín Quijano Mariluz e Isolina Vega Vidal, y familiares inmediatos con actividades similares a las de casi todas las familias del lugar. Los barrios nucleares y contiguos de la ciudad capital del distrito, entre dos quebradas paralelas que corrían de sur a norte, eran Ramos Capilla en la parte alta y el de la plaza de Armas en la parte baja, los dos unidos por el empedrado jirón 28 de Julio, que apenas tenía una longitud de dos o tres cuadras. A su vez, cada uno de ellos tenía una periferia de viviendas algo dispersas con sus respectivos huertos y espacios para la crianza de animales o para el cultivo de alfalfa y hortalizas. También, a distancia, un poco mayores en todas las direcciones, había grupos de casas con corrales y terrenos de cultivo algo más extensos 
(Panri, Shogush, Huamash-kunkan, Pacpak y dos Ñahuín Puquio, uno en el extremo este y otro en el oeste, etc.); por ese entonces, en las primeras décadas del siglo XX, estos últimos podrían ser considerados como barrios en formación. Por otra parte, muchas de las familias del pueblo eran básicamente pequeños propietarios de chacras dispersas en los ya aludidos pisos ecológicos en los que, aparte de pastizales, era posible cultivar desde tubérculos, tarhui y quinua en las alturas, hasta cereales, arvejas, maíz, leguminosas, ají y ciertas frutas en las partes bajas que se prolongaban en dirección norte hasta el río Huaripampa-Yurma.

En el pueblo de Yanama no había necesariamente tradición de comunidades indígenas y de vida comunal campesina aunque, ciertamente, se trataba de campesinos indígenas quechuahablantes, descendientes de trabajadores migrantes en condición de peones. Hasta fines del siglo XIX, más o menos hasta los tiempos de la guerra del Pacífico, Yanama había sido casi exclusivamente vaquería, es decir, un espacio extenso con pastizales a donde eran llevados por temporadas enteras ganado vacuno y otros animales de propiedad de terratenientes que vivían en las llamadas zonas templadas o cálidas de la región. Hasta entonces, no existía población estable en la vaquería salvo peones indios al servicio de aquellos terratenientes-gamonales, permaneciendo allí apenas temporalmente y cumpliendo tareas de vigilancia, viviendo en chozas precarias. Desde luego, lo que hasta entonces se consideraba como "la puna de Yanama", y era utilizada como vaquería, era propiedad de estos mismos gamonales. A su vez, fueron ellos mismos, o algunas de sus fracciones o segmentos, los que en tiempos de la guerra del Pacífico o desde algunos años antes comenzaron a migrar a "su" puna. Al establecerse progresivamente allí, a $3350 \mathrm{msnm}$, sin renunciar necesariamente a sus propiedades previas, facilitaban sus viajes de negociantes partiendo desde diferentes puntos de Conchucos hacia Yungay y otras ciudades del Callejón de Huaylas para luego trasladarse a la costa y básicamente a Lima.

En aquel pueblo de Yanama, ya visible como ciudad en gestación, desde comienzos del siglo XX funcionaba alguna que otra escuela y hacia adelante fue siendo gestionada la creación oficial de dos escuelas, una de mujeres y otra de varones, en un principio hasta el tercer año de primaria y luego hasta el quinto año. Estos logros se afianzaron con la creación política del distrito de Yanama, en 1920, y su pertenencia a la provincia de Yungay. Los niños de los barrios nucleares, como todos los del pueblo, conforme alcanzaban los seis o siete años de edad, hacían su ingreso a la escuela de mujeres o a la de 


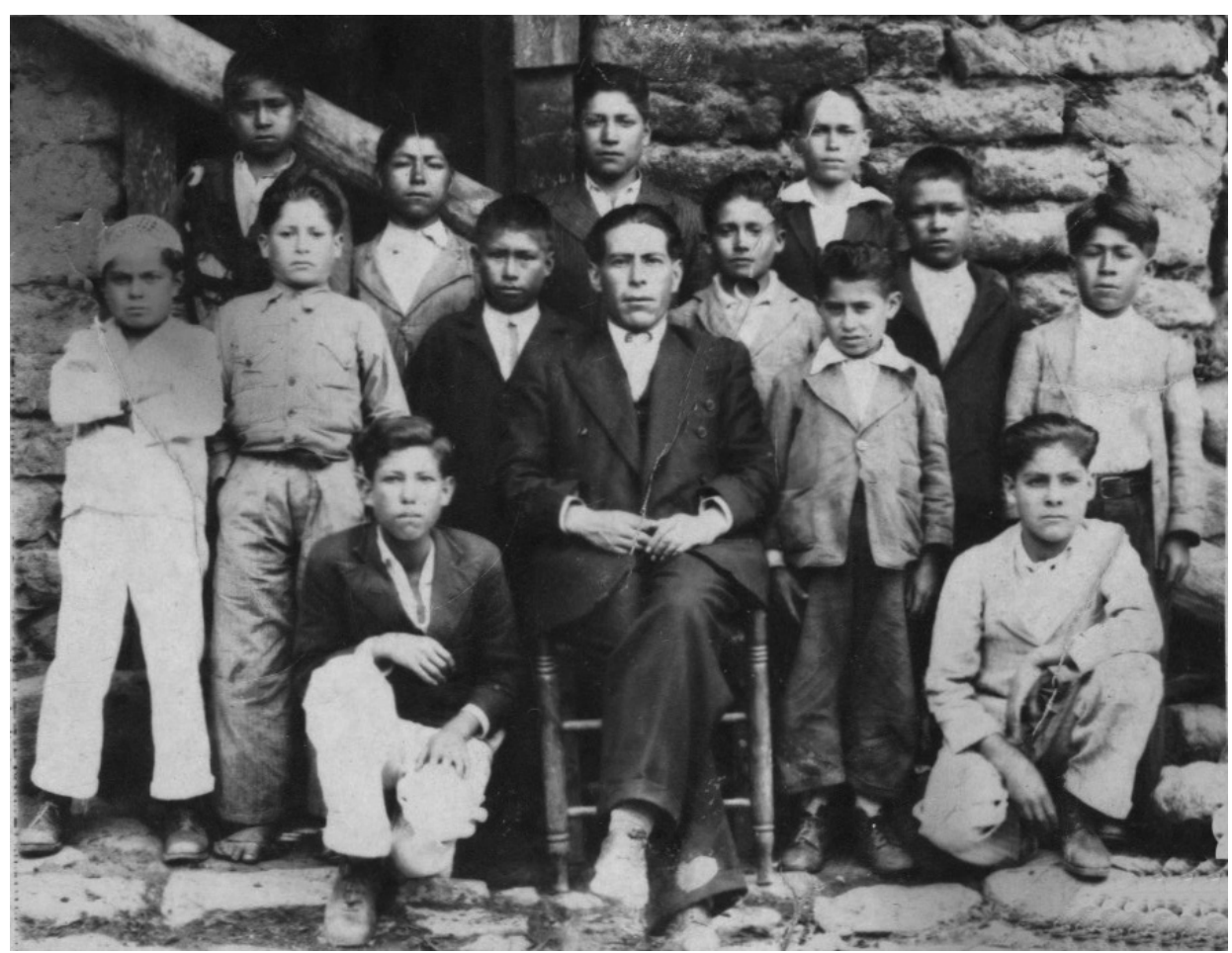

Aníbal en su escuela de Yanama con sus compañeros y profesor.

varones, respectivamente; la mayoría de alumnos lo hacían hasta culminar el quinto año de primaria y los demás, unos pocos, solo hasta el tercer año. Estos últimos luego eran llevados por sus padres a la ciudad de Yungay, capital de la provincia, para proseguir sus estudios de cuarto y quinto año de primaria y luego ingresar al Colegio Nacional Santa Inés para cursar sus estudios de secundaria. En este sentido, es probable que sus tres primeros años de primaria Aníbal los cursara en 1938-1940 en la escuela de Yanama, cuyo director era precisamente su padre Marcial. Allí encontró que muchos de sus compañeros de estudios eran hijos de campesinos quechuahablantes o "indios" y que varios de ellos eran conocidos amigos suyos debido a sus cotidianas andanzas infantiles en la calle o en lugares vecinos.

La lengua dominante en toda la zona de Conchucos era el quechua el que, a su vez, estaba difundido en el Callejón de Huaylas y otras zonas del Perú central y en gran medida vigente hasta hoy con sus respectivas variantes (Parker y Chávez, 1976; Torero, 1974). El director y los demás profesores, desde el primer día y todo el tiempo, impartían las clases en quechua y español. El 
trabajo docente, con participación activa de los propios alumnos, consistía en la traducción oral del idioma oficial al quechua y viceversa; igual cosa ocurría con los textos oficiales de lectura y en todos los aspectos de la vida escolar. En ese sentido, todos los escolares y sus profesores manejaban fluidamente las dos lenguas, eran bilingües. En consecuencia, sus conocimientos de las cosas en general, más aún en constante contacto con la naturaleza, revelaban siempre una mayor asimilación del pensamiento andino o "indígena". Esta fase de la vida estudiantil escolar fue sin duda bastante significativa para todos los alumnos, y particularmente para Aníbal, quien vivía experiencias simultáneas respecto de sus relaciones de amistad con el campesinado indígena y los niños indios y su padre, quien con su reconocida autoridad intelectual era públicamente un serio defensor de la "raza" indígena, identificado con sus protestas y reclamos frente al gamonalismo de la región y solidario con ellos ante la explotación y dominación de las que eran víctimas y en especial ante la discriminación racial. Al mismo tiempo, don Marcial era considerado no solo el eminente maestro de la escuela, sino también el médico estudioso y conocedor de los problemas de salud de todo el distrito y sus estancias, cuya población era mayormente campesino-indígena. En cierto sentido, era heredero y continuador de su padre don Agustín, pero actualizando siempre sus conocimientos en sus viajes a Yungay, Huaraz y Lima, en contacto con profesionales del área y con la literatura respectiva. Pero esta ya es otra historia.

\section{Vivir en los tensos años de las décadas de 1930-1940 en Yungay, Yanama y la región}

Como estaba programado por la familia y en cierto modo por la tradición local, Aníbal fue llevado a Yungay donde debía proseguir sus estudios de cuarto y quinto año de primaria, los cuales los tuvo que hacer en 1941 y 1942. De esta manera se sumó a sus hermanas mayores que con los mismos propósitos ya residían allí. Y al igual que ellos, eran trasladados a Yungay algunos otros grupos de niños o adolescentes del mismo pueblo o de las ya mencionadas estancias. Se trataba de familias que en cierto modo podían costear las residencias de sus hijos en viviendas alquiladas y bajo el cuidado de una empleada procedente del mismo lugar o, ya siendo colegiales, podían vivir en pensiones. Vivir en Yungay significaba, obviamente, tener que viajar varias veces al año entre dicha ciudad y Yanama, y viceversa, 


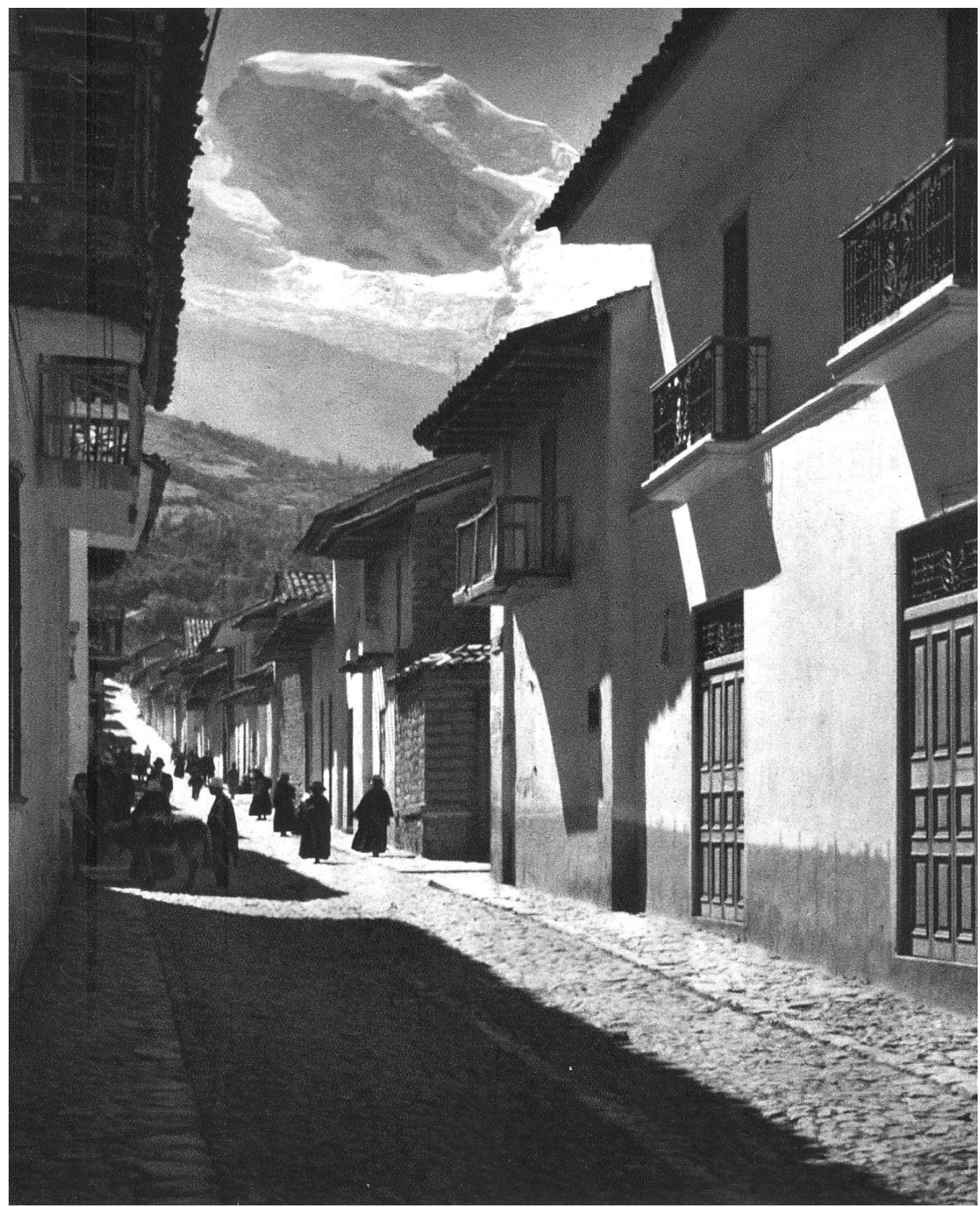

La antigua ciudad de Yungay en 1932. Jirón 28 de Julio y el Huascarán al fondo.

con motivo de las vacaciones escolares, a lomo de bestia por el accidentado camino de herradura de unos sesenta kilómetros de longitud, durante diez o más horas. Al partir de Yungay, se contemplaba por ratos el imponente nevado Huascarán, las lagunas de Llanganuco, se las bordeaba por el excepcional desfiladero de Barbacoa, recorriendo a trote el camino de Yuracc- 
Corral para luego ascender al Portachuelo (La Punta), a 4800 msnm, y terminar descendiendo con la laguna de Morococha a la vista. Se trataba, desde luego, de viajes de ida y vuelta entre el Callejón de Huaylas y la región de Conchucos (Valladares, 2011).

Luego de culminados sus estudios en la escuela primaria, Aníbal llevó a cabo los de secundaria, entre 1943 y 1947, en el Colegio Nacional Santa Inés de la misma ciudad de Yungay. En el Callejón de Huaylas también existían el Colegio Nacional Dos de Mayo de Caraz y el Colegio Nacional La Libertad de Huaraz. En esos tiempos ocurrían graves sucesos o problemas nacionales e internacionales, susceptibles de ser percibidos no solo por muchos de los docentes sino también por adolescentes inquietos que precisamente transitaban por la vida colegial. Entre sus compañeros, Aníbal era quizás quien mejor conocía y percibía el sentido de los acontecimientos y hechos políticos en el Perú como, por ejemplo, los que ocurrían en medio de tensiones y conflictos entre el APRA antioligárquico y antiimperialista en la clandestinidad y la oligarquía y sus apéndices por el control vitalicio del poder del Estado. En ese trance, ocurrieron las luchas políticas para las elecciones generales de 1945 y la conformación del Frente Democrático Nacional, cuya fuerza principal era precisamente el APRA, con la capacidad de movilizar pueblos y grandes sectores de trabajadores y juventudes. A nivel internacional, estaba en marcha la Segunda Guerra Mundial (1939-1945) desencadenada por las oscuras fuerzas del nazismo por el control del poder en la Alemania del III Reich.

En ninguno de los casos se trataba solo de casualidades o novedades pasajeras en la vida de un joven o de grupos de jóvenes colegiales. Se trataba de toda una época cuyo escenario era nacional y mundial. En el caso particular de Aníbal ocurría, pues, que su padre Marcial Quijano había estado contribuyendo, a través de su propia vida como ciudadano y maestro, al temprano desarrollo de una sensibilidad política antioligárquica, antigamonal y antidictatorial en su hijo. Como muchos maestros peruanos de su generación, desde fines de la década de 1920 y en la candente década de 1930 había sido atento lector de los escritos de Haya de la Torre y José Carlos Mariátegui quienes, a su vez, fueron protagonistas de importantes debates teóricos y políticos, particularmente entre 1927 y 1929, hechos que al mismo tiempo llevaron a una ruptura histórica y a la constitución de dos significativas corrientes ideológico-políticas en la sociedad peruana: por un lado, la corriente democrático-nacional expresada en el APRA y, por otro, la corriente socialista revolucionaria expresada en el Partido Socialista del Perú. 
Aníbal había descubierto tempranamente, durante algunas de sus vacaciones de colegial, que entre los papeles y algunos libros de don Marcial estaban guardados los 7 ensayos de interpretación de la realidad peruana de Mariátegui y algunos ejemplares de la revista Amauta, de la cual este mismo escritor había sido fundador y director (Alba Herrera, 2016). ${ }^{2}$ Los 7 ensayos..., con el enfoque y visión fundamentalmente marxistas de su autor, contenía escritos críticos y trascendentales que iluminaban y esclarecían los problemas históricos de la sociedad peruana, tales como el problema del indio, el problema de la tierra, el proceso de la instrucción pública, el proceso de la literatura presentando en especial las figuras de escritores como Ricardo Palma, Manuel González Prada, Abraham Valdelomar, César Vallejo, Magda Portal, entre otros. Además, no se le podía escapar a ningún lector atento lo que por entonces era una consistente caracterización de la economía y sociedad peruana como semifeudal y semicolonial. A su vez, Amauta había sido una revista de debate y definición ideológica.

En medio de esta realidad provinciana y regional, el estudiante Aníbal Quijano ocupó el primer puesto en todos y cada uno de los años de su vida colegial. Al egresar como integrante de la promoción de 1947, en el acto público de clausura el Colegio Nacional Santa Inés lo premió haciéndole entrega de la entonces afamada novela La cabaña del tío Tom, de la escritora norteamericana Harriet Beecher Stowe, que hablaba del negro y de las condiciones de su existencia esclava. ${ }^{3}$ La lectura de dicha obra, habría acentuado los sueños e intenciones de Aníbal por estudiar e investigar más adelante la historia del negro. Lo intentó hacer más tarde, consultando infinidad de documentos coloniales, en la década de 1950, siendo estudiante universitario y, a la vez, empleado del Archivo General de la Nación.

Respecto de las luchas políticas en el Perú de las décadas de 1930-1940, habría que destacar algunos de sus rasgos fundamentales difundidos en todas las provincias y regiones. En los pueblos de Conchucos y del Callejón de Huaylas, aún quedaban en el recuerdo ciertas huellas del elevado nivel teórico e ideológico que había alcanzado el debate entre Haya de la Torre

\footnotetext{
Prólogo de Aníbal Quijano al libro de Alba Herrera (2016).
}

3 La primera edición de esta novela era de 1852, y hasta fines del siglo XIX había tenido innumerables ediciones en diferentes idiomas hasta alcanzar los tres millones de ejemplares, acicateadas en gran medida por la guerra civil norteamericana (1861-1865). Esta tendencia expansiva de su difusión se había mantenido durante la primera mitad del siglo XX y, en especial, en las vísperas de cumplirse el primer centenario de su primera edición. La principal editora y distribuidora en América Latina era la editorial Tor de Buenos Aires, una de cuyas prioridades era la publicación de novelas clásicas. 
y José Carlos Mariátegui, especialmente entre los años decisivos de 19271929. Muchas de esas huellas, como en cualquier provincia o en el país entero, se mantenían ocultas o escondidas en los domicilios o en las conciencias frente a la represión de los Gobiernos dictatoriales y oligárquicos como los de Sánchez Cerro (1931-1933), Óscar R. Benavides (1933-1939) y Manuel Prado (1939-1945). Es sabido que, por un lado, con la temprana muerte de Mariátegui en abril de 1930, desaparecieron del debate nacional las ideas y el pensamiento socialista revolucionario que él había desarrollado y, por otro, predominaban en la escena el pensamiento y discurso apristas, convirtiéndose este movimiento en la dirección política hegemónica de los trabajadores y el grueso de explotados y dominados.

En esta situación, los famosos cinco puntos del programa máximo del APRA y la letra y música de "La marsellesa aprista" vivían su plenitud en las mentes y latidos de apristas de todas las generaciones y profesiones, de los llamados "trabajadores manuales e intelectuales", en medio de las más difíciles condiciones de clandestinidad, corriendo graves riesgos como las delaciones, persecuciones, cárceles y asesinatos. Año tras año, esa situación atravesada por fuertes tensiones era la dominante en la atmósfera política provinciana y nacional. Muchos de esos apristas eran precisamente maestros de escuelas y colegios. Segmentos significativos de estudiantes de secundaria no ignoraban nada de eso sino, más bien, se sentían comprometidos. En conflicto con el discurso aprista, circulaban no tanto las ideas socialistas revolucionarias de Mariátegui sino, más bien, las del Partido Comunista Peruano, dirigido por funcionarios de la III Internacional como el señor Ravines. Grupos de comunistas en las diferentes ciudades del Callejón de Huaylas se consideraban partidarios de Mariátegui, pero desconocían que sus "sucesores" habían declarado a manera de consigna "desamautizar" la revista Amauta y "desmariateguizar" el partido de Mariátegui (Alba Herrera, 2016).

En suma, en las décadas de 1930-1940, el APRA en su lucha por el poder se enfrentaba, más que a la oligarquía misma, a dos movimientos duramente adversarios suyos: por un lado, un socialismo ajeno a la herencia de Mariátegui que se denominaba Partido Comunista Peruano, y que en el periodo 1939-1945 aparecía como aliado del Gobierno plutocrático de Prado a quien declaró como el "Stalin peruano"; por otro lado, el partido Unión Revolucionaria de tendencia fascista que había apoyado a Sánchez Cerro y a Benavides, y era dirigido por caudillos como el abogado Luis A. Flores y ciertos miembros de la familia Miró Quesada, propietaria de El Comercio (Molinari, 2017, 2006). 
Por espacio de casi quince años, fue generalizado e intenso en el Perú el impacto de la persecución a los apristas desde el poder del Estado y, a su vez, de la resistencia y las catacumbas apristas en la clandestinidad, desde los tiempos de la insurrección popular de Trujillo, en 1932, y los sucesos locales de Huaraz, Cajamarca y Huancavelica en esas mismas circunstancias. En los casos de los pueblos de Yungay y del Callejón de Huaylas, el espíritu de la resistencia aprista era aún más fuerte, al ser revitalizada de manera recurrente la memoria histórica de la rebelión campesino-indígena de Atusparia y Pedro Cochachín (1885) y las andanzas del bandolero social Luis Pardo en la primera década del siglo XX (Zubieta, 2016; Alba Herrera, 2000).

\section{Primeros tiempos de Aníbal en Lima y en la Universidad Nacional Mayor de San Marcos}

Aníbal Quijano, en compañía de su padre, llegó a Lima a comienzos de 1948. Fue recibido en una modesta vivienda en el jirón República Dominicana 351, frente al mercado del distrito de Jesús María, donde vivía don Félix Quijano

Vega, hermano menor de su padre, un guardia

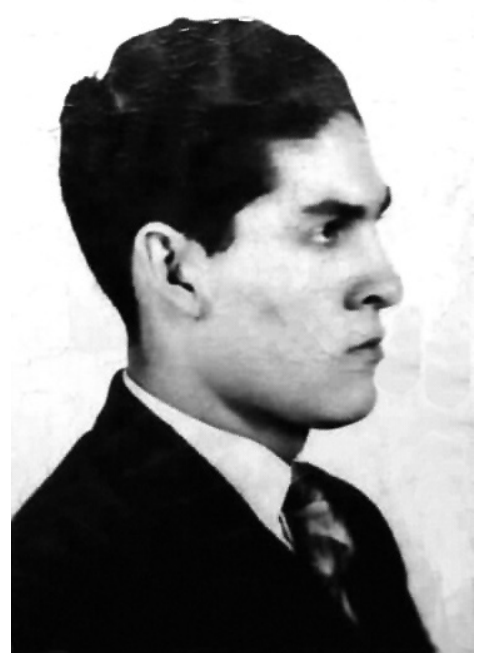

Aníbal en los inicios de 1948. civil y activo militante aprista. Aquel año era de la más intensa agitación política en Lima y en todo el país. Se encontraban enfrentados, por un lado, el conservador y opaco Gobierno de Bustamante y Rivero y, por otro lado, el APRA que para no pocos de sus seguidores y adversarios aún conservaba su aureola de movimiento revolucionario nacionalista, antioligárquico y antiimperialista. Las primeras visitas de Aníbal fueron a la Casa del Pueblo de la avenida Alfonso Ugarte. Llegaba allí como dirigente de la Juventud Aprista Peruana (JAP) de Yungay. Al poco tiempo, ingresó a la Facultad de Medicina de San Marcos. Como militante aprista, se incorporó de inmediato a las actividades y tareas del partido. Bajo las sistemáticas críticas y demandas políticas del APRA ante el poder, la contraofensiva del Gobierno era cada vez más agresiva. En aquellas circunstancias de agudización de los conflictos, 
ocurrió la sublevación aprista del 3 de octubre de 1948, con participación protagónica de la Armada peruana y segmentos del partido; pero esta misma fue derrotada tanto por el Ejército y la Aviación como por las contradicciones internas entre los dirigentes, los diferentes escalones y las bases partidarias apristas. Comenzaron entonces las venganzas y persecuciones contra los líderes y cuadros de dicho partido. A través del Ministerio de Educación fue impartida, por ejemplo, la orden para que Luis Alberto Sánchez no pudiera continuar ejerciendo su función como rector de San Marcos; lo desestabilizaron y arrinconaron con todo tipo de maniobras, hasta obligarlo a renunciar a su cargo y a salir nuevamente al destierro, el que ya había sufrido durante el periodo 1932-1945. Una vez más, el "zorro plateado" del APRA se fue a Santiago de Chile.

Días después, el 27 de octubre de 1948, ocurriría el golpe de Estado que derrocó al presidente Bustamante y Rivero. Contra aquel golpe militar acaudillado por su ministro de Gobierno, el general Odría, en distintas partes del país se desencadenaron protestas y movilizaciones populares, como la revuelta estudiantil con la toma de la antigua casona de San Marcos, en el parque Universitario. La dictadura actuaría con brutalidad, haciendo que sus puertas fueran derribadas por las tanquetas; capturaron y llevaron a prisión numerosos estudiantes, entre ellos Aníbal Quijano y sus compañeros apristas. Estuvieron en condición de presos políticos en el penal El Sexto, de la avenida Bolivia, durante algo más de dos años. ${ }^{4}$ Entre aquellos presos también había comunistas del Partido Comunista Peruano, trotskistas y quizás algunos liberales radicales. Eran frecuentes los debates entre ellos. Había un común respeto y admiración por la Unión Soviética, aún más, después de su aplastante victoria sobre las fuerzas nazistas de Hitler y, al mismo tiempo, también críticas a la burocratización del Gobierno y el Partido Comunista soviéticos. Pero los comunistas peruanos no los admitían de modo alguno y, a su vez, tampoco avanzaban un solo ápice, aparte de su ciega defensa y devoción por Stalin y el Estado de la URSS, en la actualización de sus conocimientos y reflexiones. No podían ni querían admitir lo que era notorio para muchos en la propia Europa y en América Latina: que el triunfo de la URSS en la contienda bélica y la conformación del "campo socialista" no significaban necesariamente el triunfo ni la continuidad de la revolución socialista, y menos aún la construcción de la nueva sociedad socialista.

4 Sobre aspectos críticos de la época y la coyuntura, véase los trabajos de Villanueva $(1975,1973)$. 
Ya en la cárcel, con cierta frecuencia, los presos políticos recibían por parte de sus familiares una serie de publicaciones, pero no las de carácter político-partidario. A pedido de Aníbal, el tío aprista y policía le llevaba básicamente obras literarias entre novelas, cuentos y poemas. Entre las noticias políticas que recibían, las más abundantes eran las referentes a la feroz represión antiaprista, como la que acabó con la vida del líder obrero y secretario general del APRA Luis Negreiros Vega en marzo de 1950. En el campo ideológico y político, algunos o muchos apristas se alejaban de su partido, y en esas mismas circunstancias Aníbal transitaba del aprismo al socialismo revolucionario. ${ }^{5}$

\section{Transición del aprismo al socialismo revolucionario en la década de 1950}

Al cabo de infinidad de gestiones fundamentalmente de carácter familiar y amical, Aníbal fue liberado. Luego de una breve visita a su pueblo y familiares de Yanama y de una estancia de algunos meses en Chimbote, ayudando en los pequeños negocios de otro tío paterno, se reincorporó a San Marcos e hizo su traslado a la Facultad de Letras y Humanidades. Allí llevaría cursos de Historia, Arqueología y Antropología, Filosofía, Literatura, etc., contando con profesores del más alto nivel académico. ${ }^{6}$ De otro lado, aún en plena dictadura de Odría, eran frecuentes los debates ideológicos y políticos en los viejos patios y corredores de San Marcos, entre estudiantes de las diversas tendencias de izquierda. Uno de los problemas que los enfrentaba tenía que ver con el socialismo revolucionario y el destino de la URSS. Los críticos de esta potencia vencedora de la Segunda Guerra Mundial simplemente eran satanizados por los comunistas con una serie de descalificaciones como "enemigos de la revolución", "traidores", "trotskistas", etc. Esta era la eterna letanía de los viejos y jóvenes militantes del Partido Comunista Peruano, es decir, con ellos no era posible debate teórico-ideológico alguno y siempre se mantuvieron irreductibles en esa posición (Vargas Llosa, 1991).

5 Conversaciones recurrentes con familiares, amigos y expresos políticos, en especial con don Félix Quijano Vega, en la década de 1960; también confesiones indirectas y fragmentarias del propio Aníbal.

6 Entre dichos profesores, pueden ser mencionados Raúl Porras Barrenechea, Ela Dunbar Temple, Alberto Tauro del Pino, Jorge Basadre, Luis Valcárcel, Jorge Muelle, Jorge Puccinelli, Estuardo Núñez, José Russo Delgado, José Jiménez Borja, Augusto Tamayo Vargas, entre otros. Además, por esos tiempos, venían al Perú numerosos arqueólogos y antropólogos de Estados Unidos y Europa. 
Entre tanto, básicamente por cuenta propia, Aníbal estudiaba historia y teoría marxista. Quizás hacia 1953 o 1954 le envía una larga carta a su padre hablándole de sus nuevos planes y proyectos, y contándole que llevaba algunas semanas leyendo el Anti-dühring de Frederic Engels, obra de crítica y debate en los campos de la filosofía, la economía política y el socialismo. A su vez, le decía que entre sus planes estaba la adquisición sistemática de obras marxistas. En los comienzos de la década de 1960, pudimos conocer su biblioteca y ver que, además de literatura latinoamericana, tenía las principales obras de Karl Marx, Frederic Engels, Vladimir Ilich Lenin, León Trotsky, etc. También, le contaba a su padre haber retornado a escribir sus poemas, luego de haber perdido un grueso manojo de ellos titulado "Glauco Mar", en algunas de las varias incursiones policiales a su domicilio. Igualmente, le hablaba que luego de las frustrantes experiencias de dirección política partidaria vividas por los trabajadores y los pueblos del Perú, en sus luchas por el poder, se encontraba afirmando sus convicciones acerca de la necesidad de construir un nuevo discurso revolucionario con la mayor autonomía intelectual posible. Al mismo tiempo, dedicaba algunas horas del día a trabajar por unos cuantos soles. ${ }^{7}$

Simultáneamente, en el transcurso de la década, Aníbal hacía parte activa de la Generación del 50 que aglutinaba a estudiantes universitarios o jóvenes profesionales que se consideraban fundadores o protagonistas de una nueva época después de ocurridos los graves desaciertos del APRA como dirección política hegemónica de las luchas por el poder en la década previa, la incompetencia política del presidente Bustamante y Rivero y su Gobierno para conducir el país contra el poder oligárquico y por la afirmación de la senda democrática tan afanosamente alcanzada, el golpe militar de octubre de 1948 del general Odría, la derrota de la "primavera democrática" y el retorno de una dictadura aún más feroz que las anteriores. Al mismo tiempo, venían ocurriendo masivas y recurrentes migraciones del campo a la ciudad, la emergencia del problema urbano y las barriadas en expansión frente a un Estado crónicamente incapacitado para conducir los cambios económicos y sociales como los que se presentaban. ${ }^{8} \mathrm{Al}$ terminar la dictadura de Odría, muchos de los integrantes de la Generación del 50, especialmente escritores y poetas,

7 Junto con paisanos y amigos, trabajó por un tiempo en el inmenso local del cine República, cumpliendo tareas de limpieza en horario nocturno y donde otro tío paterno como administrador de personal.

8 Entre algunos de los integrantes de los altos rangos de aquella generación se puede mencionar a Julio Ramón Ribeyro, Alberto Escobar, Washington Delgado, Francisco Carrillo, Oswaldo Reynoso, Alejandro Romualdo, Pablo Macera, Carlos Araníbar, Juan Pablo Chang, Guillermo Lobatón Milla, Alfonso Barran- 
comenzaron a publicar sus trabajos de creación. Manuel Scorza capitaneó una masiva difusión a nivel nacional de la producción intelectual correspondiente a las etapas previas de la historia peruana y, desde luego, de los propios de la Generación del 50. Así aparecieron desde 1956 las ediciones del Patronato del Libro Peruano, cuya distribución y comercialización llegó a casi todas las provincias del país. El propio Aníbal participó en la publicación de cuentos y ensayos por él seleccionados. Quizás hacia 1958 hizo llegar a su padre don Marcial una colección de cuentos entre los que se encontraba Los gallinazos sin plumas, de Julio Ramón Ribeyro, y otra colección que incluía Ensayos escogidos de Manuel González Prada, por Augusto Salazar Bondy, y, además, Ensayos escogidos de José Carlos Mariátegui y Los mejores cuentos latinoamericanos, ambos preparados por Aníbal Quijano. Aparte, en el transcurso de esos mismos años, cultivaba una temprana y singular amistad con el escritor José María Arguedas y su esposa Celia Bustamante.

Por esos mismos tiempos, al culminar sus estudios en el Departamento de Historia de San Marcos y luego de dejar su trabajo de varios años en el Archivo General de la Nación, Aníbal se desempeñó como profesor en el Colegio Nacional Alfonso Ugarte, en el Colegio Franco-Peruano y en la Universidad Nacional Enrique Guzmán y Valle, La Cantuta. Luego de su matrimonio con Carmen Pimentel Sevilla y del nacimiento de su primer hijo, en 1959 viajaría en condición de becado para hacer estudios de maestría en la FLACSO de Santiago de Chile. Luego de numerosas entrevistas y largas conversaciones con Quijano, fue el prestigioso sociólogo y peruanista francés Francois Bourricaud quien recomendó su viaje a la capital chilena donde permaneció por espacio de tres años.

\section{Docencia universitaria, investigaciones y debate político 1962-1966}

Al retornar al Perú a comienzos de 1962, como magíster en Sociología, Aníbal ingresó a trabajar como profesor y director del departamento de Ciencias Sociales de la Universidad Nacional Agraria de La Molina y, también, como profesor del departamento de Sociología en la Facultad de Letras de San Marcos. En esta etapa sistematizó y profundizó sus estudios e investigaciones sobre la realidad histórica peruana. Sus investigaciones y labor docente

tes Lingán, Hernando Aguirre Gamio, Ismael Frías Torrico, Francisco Bendezú, Eleodoro Vargas Vicuña, Carlos Eduardo Zavaleta, Javier Sologuren, Manuel Scorza, Abelardo Oquendo, entre otros. 
siempre despertaron el más vivo interés y entusiasmo de sus alumnos en las dos universidades. Los problemas de investigación significaban no solo rigor metodológico e intelectual, sino también un nivel de compromiso vital con los hechos y acontecimientos del Perú y América Latina de esos tiempos bajo el impacto de la Revolución cubana, como eran los movimientos guerrilleros en diferentes países de la región. En el Perú, se tenían las luchas campesinas de Lares y La Convención bajo la dirección de Hugo Blanco, la osadía juvenil de Javier Heraud y otros camaradas suyos que cayeron en Puerto Maldonado, las guerrillas del Ejército de Liberación Nacional (ELN) y del Movimiento de Izquierda Revolucionaria (MIR), todas ellas tempranamente contenidas o derrotadas por la contraofensiva del Estado oligárquico.

Por otra parte, Aníbal retomó con entusiasmo y pasión sus andanzas con buena parte de los integrantes de la Generación del 50 y muchas de sus reuniones abiertas y casi públicas continuaban haciéndose en el afamado café Palermo de la avenida La Colmena. Se conversaba y discutía cuestiones de literatura, historia y antropología, de filosofía y política. ${ }^{9}$ Además de conocidos peruanistas como John Murra a quienes recibía con frecuencia, una de las excepcionales visitas que recibió fue la del sociólogo europeo-norteamericano André Gunder Frank, quien recorría América Latina llamando a estudiar y debatir problemas como el "capitalismo, desarrollo y subdesarrollo", "América Latina, lumpen-desarrollo y lumpen-burguesía", etc. Entre las publicaciones de Aníbal en esa época, pueden ser recordadas "El movimiento campesino peruano y sus líderes", "C. Wrigth Mills, conciencia crítica de una sociedad de masas", "Imagen saintsimoniana de la sociedad industrial", "La emergencia del grupo cholo y sus implicancias en la sociedad peruana", "Imagen y tareas del sociólogo en la sociedad peruana", "Movimientos campesinos contemporáneos en América Latina". Otros trabajos en preparación, como los del proceso de urbanización y marginalidad social, fueron publicados en los años siguientes, ya cuando nuevamente residía en Chile y bajo el calor de los debates de la teoría de la dependencia. Se debe recordar, además, que en junio de 1965 Aníbal participó en un debate con motivo de la presentación de la novela Todas las sangres de José María Arguedas, y cuyos comentarios — los de Aníbal - levantaron polvareda de talante criollo buscando hacer aparecer al autor de la novela como víctima de agresión de los sociólogos. Por un tiempo,

9 Una visión polémica sobre aquella generación, y donde Quijano aparece criticado o casi vapuleado con furia, se encuentra en Gutiérrez (1988). Quijano nunca lo leyó. Quizás la razón principal de aquella furia era su crítica enérgica, firme y sistemática contra el stalinismo. 
los forjadores de humo quizás lograron su cometido; pero una coyuntura de larga duración se encargó de restablecer en el imaginario colectivo la inquebrantable amistad entre Quijano y Arguedas. ${ }^{10}$

\section{Otra vez en Chile, la teoría de la dependencia y experiencia cosmopolita}

A fines de 1965 o a inicios de 1966, ya con dos hijos, Aníbal se vio obligado a tener que viajar nuevamente a Chile por razones de trabajo. El rector de la Universidad Agraria no le renovó su contrato como docente y director del Departamento de Sociología. Inicialmente, en Santiago de Chile fue acogido en un centro de estudios de historia latinoamericana dirigido por Rolando Mellafe. Después de un tiempo, ingresó a trabajar en la División de Asuntos Sociales de la CEPAL, donde permaneció hasta comienzos de 1971. En esa etapa de su vida pudo viajar a distintas partes del mundo para dictar conferencias y participar en incontables debates sobre América Latina y los problemas internacionales. En ese entonces predominaban los debates de la teoría de la dependencia y Aníbal fue uno de sus protagonistas tanto como Fernando Henrique Cardoso, Enzo Faleto, Vania Bambirra, Theotonio Dos Santos, María Concepción Tavares, Ruy Mauro Marini y muchos otros, como Gunder Frank, quien había decidido vivir en Chile. Cada uno de ellos se destacaron por sus numerosas y frecuentes publicaciones. ${ }^{11}$

Algo que merece destacarse es que, durante esta segunda etapa de su estadía en Santiago de Chile, Aníbal mantenía frecuente comunicación con intelectuales de su generación y con grupos de estudio y debate que en algunos casos se proponían organizarse políticamente, y en otros solo participar en investigaciones y debates de carácter marxista sobre problemas peruanos. En más de una oportunidad viajó a Lima para dictar conferencias en universidades como San Marcos y la Universidad de Ingeniería (UNI), y también para discutir en reuniones restringidas la coyuntura peruana y latinoamericana. Un viaje más al Perú lo hizo días después del violento terremoto del 31 de mayo de 1970, para visitar Yungay, la señorial y hermosa ciudad ya inexistente, que había sido sepultada por el aluvión de ese día y donde desaparecieron su

10 Véase Rochabrún (2011).

11 Acerca de los trabajos publicados por Aníbal Quijano en aquellos años de la CEPAL y en otras etapas de su trayectoria intelectual, véase Quijano (2014). 
padre, muchos familiares e incontables amigos. También visitó Yanama solo para encontrar su casa habitada por el silencio (Valladares, 2011).

\section{Nuevamente en el Perú, Sociedad y Política y combates contra el Gobierno militar}

A comienzos de 1971, Aníbal Quijano renunció a la CEPAL y retornó al Perú, habiendo escrito dos trabajos acerca del Gobierno Revolucionario de las Fuerzas Armadas: "El golpe militar en el contexto peruano y latinoamericano" (con el seudónimo de Ramón Collar) y "Nacionalismo, neoimperialismo y militarismo en el Perú". Aníbal volvía al Perú como un teórico marxista mucho más consolidado, habiendo participado a lo largo de cinco años en encuentros y debates en distintas partes del mundo, confrontando sus investigaciones y reflexiones con intelectuales marxistas o no de diferentes países. Vino a su país dispuesto a enfrentar ideológica y políticamente al Gobierno militar y contribuir a la construcción de la dirección política revolucionaria de los trabajadores y del conjunto de explotados y dominados.

En el proceso de crítica y cuestionamiento al Gobierno militar, la aparición de la revista Sociedad y Política en junio de 1972 fue un hecho políticointelectual que alcanzó amplio y rápido impacto nacional e internacional. Con Quijano como director de la revista, los integrantes de su Comité de Redacción y del Comité Asesor Internacional eran también figuras conocidas y prestigiosas. ${ }^{12}$ Desde un principio, la revista fue ganando adherentes que se incorporaban de manera creciente a tareas como la distribución de la revista, tanto en Lima como en provincias, bajo la coordinación de un singular militante como Abraham Zevallos, o la organización de charlas y debates en sindicatos, federaciones, asociaciones de urbanizaciones populares, etc. Los principales problemas a los que la revista dedicaba sus páginas eran el imperialismo y el capitalismo de Estado en el Perú; el autoritarismo y el corporativismo en el Gobierno militar; la cuestión del socialismo revolucionario como movimiento antiburocrático, creador y fecundo; la crítica del stalinismo y del "socialismo

12 En principio, los integrantes del Comité de Redacción fueron: Heraclio Bonilla, Julio Cotler, César Germaná, Felipe Portocarrero y Ernesto Yépez. El Comité Asesor Internacional: Sergio Bagú (Argentina), Fernando Henrique Cardoso (Brasil), Agustín Cueva (Ecuador), Samuel Lichtensztejn (Uruguay), Edelberto Torres Rivas (Guatemala) y Rodolfo Stavenhagen (México). 
realmente existente"; la vía chilena al socialismo; las perspectivas de la clase obrera y sus tareas, etc. ${ }^{13}$

Antes y durante la publicación de esta revista, Aníbal Quijano participaba con frecuencia en actividades políticas de diferente magnitud, comenzando por reuniones con dirigentes o segmentos de trabajadores de centros fabriles de Lima-Callao, estudiantes universitarios, maestros y, también, en conferencias y debates en actos masivos en la Facultad de Letras de San Marcos y en otras universidades públicas de Lima y provincias. Entre los años 1972-1973, participó en asambleas de dirigentes y delegados mineros de la Cerro de Pasco Corporation, más tarde estatizado y denominado CENTROMIN. También, durante varios días seguidos, en asambleas de los trabajadores de SIDER-PERÚ, en su propio local sindical, con creciente público interesado, en la ciudad de Chimbote. En esta ocasión, los debates públicos se desarrollaron teniendo al frente a rudos y experimentados adversarios o enemigos políticos (excomunistas, exizquierdistas, extrotskistas, exapristas, socialcristianos, socialprogresistas, etc.), como eran especialmente los funcionarios de SINAMOS, la principal herramienta del Gobierno para pautar y amarrar verticalmente al Estado las organizaciones de los trabajadores del país. Ciertamente, al final de cuentas, resultaron mucho más rudos y lúcidos los dirigentes y delegados de los trabajadores y el propio Quijano. También la revista se articuló a segmentos significativos del magisterio organizados en el SUTEP y pertenecientes a la tendencia impulsada por Julio Pedro Armacanqui; igualmente, era bastante conocida su presencia e influencia en la CUAVES de Villa El Salvador, y cuyo principal dirigente era Apolinario Rojas; además, hacia adelante y en la misma línea, se fueron conformando movimientos en Arequipa y Puno con presencia en su Federación Departamental Campesina. Los movimientos obreros, campesinos y populares en el país se encontraban en proceso de ascenso, el mismo que se prolongó hasta 1980 o algo más a despecho de la represión de los militares en el poder y de la crisis ideológica y política que engendraría la propia izquierda (Valladares, 2013).

Los primeros cuatro números de la revista Sociedad y Política hegemonizaron el discurso de oposición de la izquierda revolucionaria ante el Gobierno militar, cuyos aliados, teóricos y funcionarios se esmeraban en querer desacreditar y liquidar, a través de la prensa oficialista, a quienes escribían en dicha

13 Al cumplirse el primer aniversario de la partida de Aníbal Quijano, la Facultad de Ciencias Sociales de San Marcos, bajo la conducción de su decano, el profesor Julio Mejía, ha publicado una edición facsimilar en un solo volumen de los trece números de la revista Sociedad y Politica. 


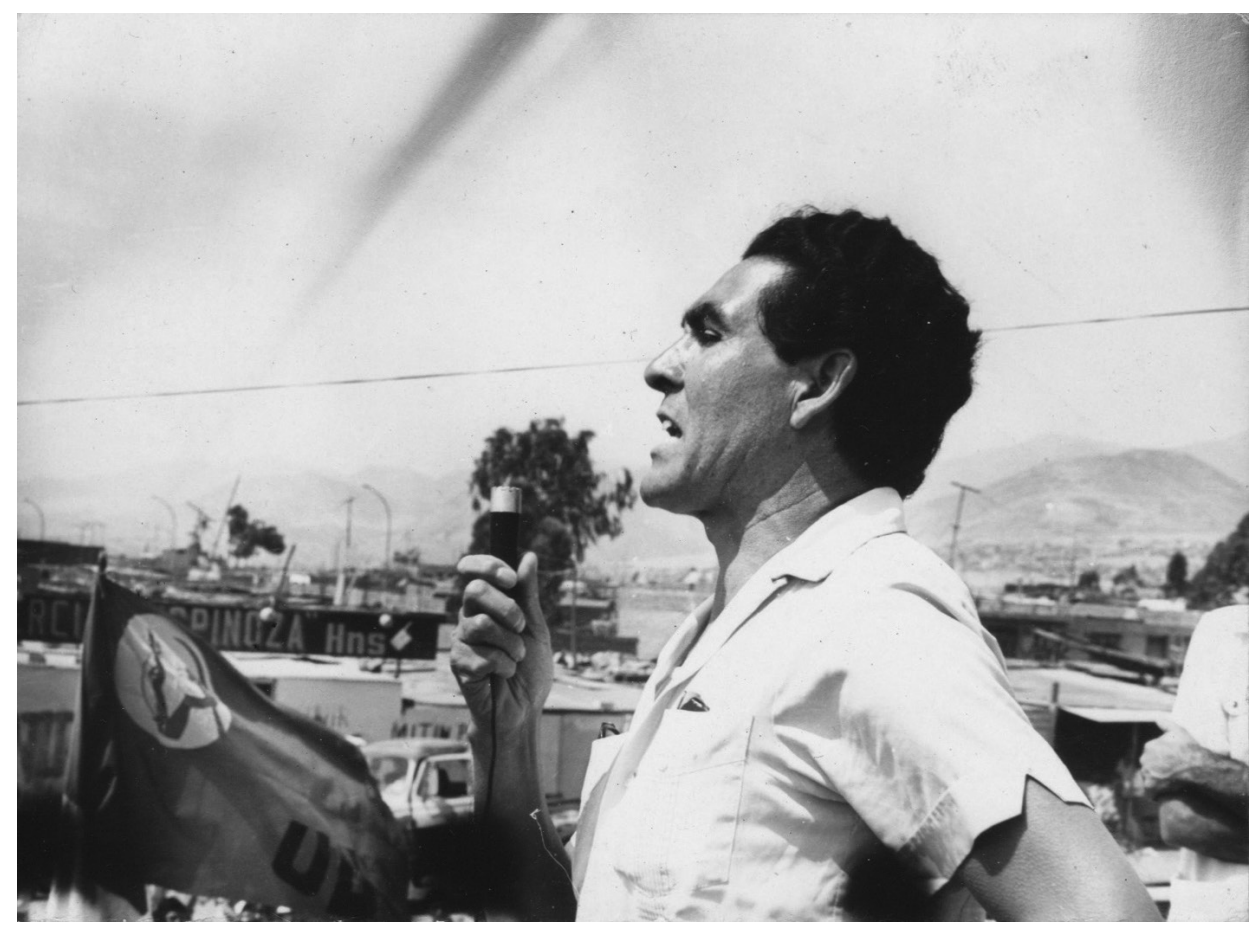

En un mitin político en Villa El Salvador, en diciembre de 1979. Aníbal pronunció su discurso a nombre del MRS, en compañía de los dirigentes de la Cuaves.

revista. Uno de los más importantes teóricos del Gobierno era el antropólogo Carlos Delgado Olivera, exaprista, bastante cercano al COAP y al propio presidente Velasco, y también viejo amigo de Quijano y Cotler, pero con quienes rompió radicalmente hasta el punto de recomendar su deportación en setiembre de 1973. Logró mandarlos al exilio sin destino conocido, sacándolos a la Argentina y desde allí, luego de circular por distintos países, encontraron refugio en México, donde se desempeñaron como profesores e investigadores en la Universidad Nacional Autónoma de México (UNAM). Ciertamente, antes de salir al destierro, aún pudieron participar en la gran movilización de masas de condena al criminal golpe de Estado que derrocó al presidente socialista Salvador Allende y en solidaridad con los trabajadores y el pueblo chileno.

Al término del exilio, y luego de dos años de interrupción, Sociedad y Política recién reapareció en noviembre de 1975, con la publicación de su número 5. Mientras tanto solo pudo mantenerse en acción el Movimiento Revolucionario Socialista (MRS), haciendo trabajos de base, logrando pu- 
blicar un boletín semanal denominado Revolución Socialista, cuyo público era básicamente obrero-sindical, con un contenido de análisis de la coyuntura política y crónicas de los movimientos y luchas sindicales. Al volver a salir Sociedad y Política, la situación nacional e internacional era otra. Había tenido lugar el estallido de la tercera gran crisis internacional de la economía capitalista (Quijano, 1974). En ese contexto, en el Perú habían sucedido graves hechos como la huelga policial y los saqueos e incendios en Lima en febrero de 1975 que hicieron trastabillar el poder político. Estos hechos precipitaron el golpe de Estado de agosto del mismo año, que derrocó al general Velasco y dio inicio a la "segunda fase" del Gobierno militar; luego se encontraba en marcha la depuración de la cúpula de las Fuerzas Armadas, pasando al retiro a oficiales que habían pertenecido al ala de izquierda del Gobierno. La derecha ganaba terreno dentro y fuera de las Fuerzas Armadas y del propio Gobierno. Estaba ocurriendo la temprana penetración del neoliberalismo en el Perú.

Ante tal situación, en la editorial de la revista se hablaba de las tareas de los trabajadores en la nueva situación política nacional. El propio Quijano escribió un extenso artículo titulado "La segunda fase de la revolución peruana y la lucha de clases", en el que se refería a la depuración de las bases sociales del Estado y las contradicciones del régimen militar, la crisis económica, la agudización de las contradicciones, la expropiación de la prensa y la aceleración del corporativismo, entre otras cosas. En ediciones siguientes (número 6 y 7), se planteaba problemas como el frente popular antiimperialista o frente de los trabajadores, el frente capitalista, la fuerza táctica y la debilidad estratégica, el nuevo plan económico, la situación de la industria manufacturera y la lucha de clases, entre otros. ${ }^{14}$ En vísperas de las elecciones generales de 1980, se hablaba (número 8) de las condiciones del enfrentamiento, ¿a dónde va el campo andino?, capas medias y poder, eurocomunismo y socialismo. Luego de las elecciones y el abrumador triunfo de Belaunde, en la editorial se hablaba (número 9) de "Belaunde y la frágil arquitectura del consenso", "¿Belaunde, un mal menor?”; "Comunidad y clase en los Andes", "China, el gran salto atrás”. En la editorial de fines de 1980 (número 10), se preguntaba “QQuo vadis, domine?”, y se hablaba de las trizaduras que habían comenzado a hacer visibles graves fallas, cómo usar la democracia, el papel y el destino

14 En Sociedad y Política números 5, 6 y 7, solo apareció Quijano como director. Recién a partir del número 8 reapareció el Comité de Redacción renovado: Roberto Arroyo, César Germaná, Mirko Lauer, Rodrigo Montoya, Peri Paredes, Felipe Portocarrero, Manuel Valladares, Abraham Zevallos. Luego se sumaron José Ignacio López Soria y Gladys Róquez. En el diseño gráfico continuó Jesús Ruíz Durán. 
del APRA, la tragedia de las equivocaciones en Bolivia, el Partido Comunista entre el poder y la revolución en Polonia.

Hacía buen rato que los militares se habían marchado a sus cuarteles y se había instalado en el Perú un Gobierno democrático conservador. En los primeros años de la década de 1980, con la mayoría de la izquierda en el Congreso y los municipios, fueron haciéndose cada vez más notorias las señales de empobrecimiento del debate político. En Izquierda Unida y su liderazgo eran crecientes las tendencias hacia el parlamentarismo y la conciliación de clases. El problema del poder dejó de estar en el debate. Al mismo tiempo, Sendero Luminoso, que había desencadenado la subversión contra el Estado a través de la lucha armada, tampoco representaba la dirección política alternativa ante los trabajadores y las masas populares. En medio de esa situación, el capital y su Estado recuperaban su antiguo poder, con el belaundismo como su mascarón de proa. Este mismo Gobierno dio inicio a una política de terrorismo de Estado en el país, la misma que continuaría por mucho tiempo. Desde luego, todo eso fue criticado enérgicamente por Quijano.

\section{Debates acerca de la socialización del poder político}

El debate sobre la cuestión de la socialización del poder político, Quijano lo había planteado con relativa frecuencia durante la década de 1970, pero en el número 12 de Sociedad y Política (en agosto de 1981) le dedica un artículo entero con el título "Poder y democracia en el socialismo". Este debate lo continuaría de manera sistemática por el resto de su vida, en tanto que uno de los componentes esenciales de sus ideas y reflexiones acerca de la colonialidad/ descolonialidad del poder. Un punto de partida de esta cuestión fue planteado por Karl Marx en su obra La guerra civil en Francia, escrita a raíz de la Comuna de París de 1871. Más tarde, Lenin le consagró un detenido y puntual estudio a esta cuestión en El Estado y la revolución, escrito en tiempos de la Primera Guerra Mundial y la revolución bolchevique de 1917. Aníbal Quijano actualiza, desarrolla y enriquece estas ideas acudiendo a la experiencia peruana e internacional de los trabajadores y sus combates a lo largo del siglo $\mathrm{XX}$. Muchas de las experiencias de las luchas de masas en el mundo habían demostrado una tendencia común hacia la organización de instancias de poder político democrático y autónomo, tipo los soviets de 1917, frente y en contra del viejo Estado, como germen del futuro Estado a ser construido no fuera ni 
sobre la sociedad sino dentro de ella. Fue precisamente con esta concepción que Quijano y la dirección de Sociedad y Política participaron en la constitución y defensa del ARI en vísperas de las elecciones generales de 1980.

No por casualidad, durante todo este tiempo, Aníbal fue testigo y actor de los esfuerzos desplegados en las luchas por la autonomía, centralización y unificación de los movimientos y organizaciones de la clase obrera, en los debates sobre una probable configuración de la situación revolucionaria y la revolución socialista en el Perú y, en especial, en la agitada y compleja coyuntura de tránsito de la dictadura militar a la democracia aparentemente liberal, entre fines de 1977 y julio de 1980. Una transición que, por un lado, logró engullirse a casi todas las organizaciones de la izquierda revolucionaria encerrándolas en la cárcel del electorerismo y el parlamentarismo y, por otro, inflando el voluntarismo de sectores y tendencias ultrarradicales y precipitándolos en el sendero de la subversión y la lucha armada. A la larga, evaporados los espejismos de aparentes triunfos, los grandes derrotados terminaron siendo los trabajadores y el conjunto de explotados y dominados por el capital. ${ }^{15}$ Quijano y Sociedad y Politica lo habían advertido.

\section{Mariátegui, reencuentro y debate}

El nombre de Mariátegui era mencionado cada vez con mayor frecuencia desde comienzos de la década de 1960 por prácticamente todos los partidos y agrupaciones de izquierda revolucionaria del Perú. Unos trataban de aparecer más mariateguistas que otros. Pero todos tenían un denominador común: glosar para la propaganda y la agitación, frases o párrafos felices, y consignas más que un pensamiento socialista revolucionario o algunas de sus líneas centrales.

Cuando Quijano habla de reencuentro con Mariátegui, significa reencuentro con el pensamiento del Amauta, con sus ideas respecto de una época, de una sociedad y sus tendencias de cambio y, en suma, toda una línea de razonamiento sobre la realidad histórica peruana en el contexto internacional. Una línea de razonamiento que recorre quizás la totalidad de sus escritos por lo menos desde su retorno de Europa al Perú en 1923. En verdad, este reen-

15 En la coyuntura 1977-1983, hubo una notoria crisis en la dirección política del movimiento obrero y de los trabajadores en el Perú. La Izquierda Unida y Sendero Luminoso, como dirección política, expresaban los extremos de dicha crisis. 
cuentro Quijano lo había iniciado durante su labor docente universitaria en la década de 1960 y lo continuaría con mayor énfasis en la década siguiente, al ritmo de su actividad política. En principio, Quijano se plantea la reconstrucción de las visiones que Haya de la Torre y Mariátegui habían desarrollado durante gran parte de la década de 1920 acerca de la realidad peruana, indoamericana y mundial, la confrontación entre ellas y, a su vez, el contraste con la realidad histórica concreta. Descubre que más allá de las palabras y las frases que podrían ser las mismas en sus escritos, se trataba de dos líneas de razonamiento diferentes y discrepantes entre sí. En otros términos, de ese modo se fue reconstruyendo la famosa polémica entre los dos destacados personajes de la historia peruana contemporánea. En ese contexto de debates protagonizados por Sociedad y Política y el MRS, el profesor César Germaná escribió su trabajo "Polémica Haya-Mariátegui", que fue publicado en Cuadernos de Sociedad y Política y adquirió enorme fama al punto de ser reimpreso frecuente y masivamente por los audaces piratas, durante por lo menos dos o tres décadas destinado básicamente al público estudiantil universitario del país.

Aquel reencuentro con Mariátegui ya no sufrió interrupciones o treguas. Más bien Aníbal continuó reconstruyendo cuestiones que en la concepción del Amauta tenían que ver con el proyecto histórico de la revolución y la construcción de la sociedad socialista en el Perú y América Latina, con el papel protagónico de las organizaciones de masas y su organización partidaria. Al mismo tiempo, se insistía en el hecho concreto de que el desarrollo y definición de las ideas de Mariátegui fue posible en gran medida gracias a su permanencia y activa participación en el histórico debate con Haya de la Torre, quien cada vez más representaba una corriente democrático-nacional. ${ }^{16}$ Quijano impulsó aún más el debate al publicar dos trabajos significativos que reafirmaban los términos de su reconstrucción crítica de la polémica mencionada. ${ }^{17}$ Luego participaría junto con Antonio Melis y otros estudiosos en los preparativos para la conmemoración del centenario del nacimiento del Amauta en 1994 y en reconocimiento a sus aportes fue el primer expositor en el gran acto de inauguración del 14 de junio. Estudios elaborados con mayor rigor acerca de la interpretación de la obra de Mariátegui por Quijano se vienen desarrollando estos años. ${ }^{18}$

16 Véase Haya de la Torre (1977) y Mariátegui (1976).

17 Se hace referencia al prólogo de 7 ensayos de interpretación de la realidad peruana (Mariátegui, 1979) y Textos escogidos de Mariátegui (1991), una selección, con prólogo y notas introductorias que hizo el propio Aníbal Quijano.

Por ejemplo, véase Ortega y Gómez Cervantes (2018) y Montoya Huamaní (2018). 


\section{La colonialidad del poder}

Más o menos en los últimos veinticinco años de su vida, Aníbal Quijano escribe y debate sobre la construcción histórica y teórica del problema de la colonialidad/descolonialidad del poder y todo lo que ello implica. Hoy en día, estas cuestiones están en pleno debate a nivel nacional e internacional, y son innumerables los estudios e investigaciones al respecto. En esta ocasión solo nos corresponde referirnos brevemente al contexto dentro del cual logró desarrollar su exigente trabajo.

En esta excepcional etapa histórica, Quijano lleva a cabo intensa actividad dentro y fuera del país. Quizás desde fines de la década de 1980 se hicieron mucho más frecuentes sus viajes para enseñar en universidades de Estados Unidos, Alemania, Puerto Rico, Venezuela, Brasil y otros países. A este ritmo de vida pudo escribir y difundir todo cuanto hoy en día se estudia y se discute. En Estados Unidos, quizás su mayor experiencia de estudios y debate la tuvo en la Universidad de Binghampton, concretamente en el Centro Fernand Braudel, fundado y dirigido por el prestigioso profesor Immanuel Wallerstein, autor de la afamada obra sobre el sistema-mundo moderno, publicada en tres volúmenes (1974, 1980 y 1989), y a quien, a su vez, se le considera precursor principal de los debates sobre la globalización. Además de influenciar en el mundo académico, sus innumerables escritos han tenido y tienen significado político trascendental, a través de sus reflexiones sobre el rol de los movimientos antisistémicos y han sido, por eso mismo, impulsores del proceso Foro Social Mundial. Al referirse a la estatura intelectual del profesor Wallerstein, el propio Quijano decía: "Como en todos los casos de genuina y básica innovación intelectual, su trabajo trasciende naturalmente los artificiales linderos entre las disciplinas dedicadas al estudio de la existencia social humana. En realidad, las afecta, las atraviesa, a todas, en la medida en que se trata de un esfuerzo dirigido a la fundación de una nueva perspectiva teórica e histórica sobre el poder contemporáneo". ${ }^{19}$

Por otro lado, en el Perú Quijano recibió una invitación del rector de la Universidad Ricardo Palma, el doctor Iván Rodríguez, para dirigir la cátedra América Latina y la Colonialidad del Poder, de la cual se hizo cargo por cerca

19 Véase su discurso "Instancias y trazos", en ocasión de serle otorgado al profesor Wallerstein el doctorado honoris causa de San Marcos, el 13 de mayo del 2004. 
de una década desde el momento en que esta misma universidad le confirió la distinción de doctor honoris causa. ${ }^{20}$

Aníbal Quijano enfrentaría, pues, una época muy difícil y compleja. Aquella que según el profesor Eric Hobsbawm es la del derrumbamiento que arranca al término del siglo XX con la crisis de valores que habían sido cuestiones esenciales de la modernidad. Esta fue anunciada por hechos casi simultáneos como el golpe de Estado de 1973 en Chile que derrocó al presidente socialista Salvador Allende y aplastó sangrientamente a su pueblo, el golpe de Estado de 1976 en Argentina tanto o más brutal y criminal que el anterior al pisotear los derechos humanos como no había ocurrido en Occidente después de la Segunda Guerra Mundial y, entre una y otra barbarie, el estallido de la tercera gran crisis de la economía capitalista internacional desencadenada en el segundo semestre de 1974 en los centros metropolitanos del sistema, con la recesión industrial y la desocupación masiva de la mano de obra asalariada y, desde luego, su demoledor impacto y reproducción en el inmenso mundo periférico del propio sistema. A diferencia de lo ocurrido después de las grandes crisis anteriores, esta vez el sistema vive una crisis económica y una desocupación crónicas. En ese contexto fueron entrando en crisis las direcciones sindicales y políticas de los trabajadores, desmoronándose sus organizaciones gremiales y partidarias, sus proyectos, sus programas y sus luchas. El neoliberalismo sentaba sus reales en todo lugar. En una mesa redonda en la vieja casona de San Marcos, en julio de 1989, con motivo del aniversario doscientos de la Revolución francesa, ${ }^{21}$ Quijano pasó revista a todo aquello que venía sucediendo en plano internacional y a la parálisis de la crítica y el cuestionamiento del poder en las grandes capitales del mundo. Así llegó a decir que "París había sido varias veces la capital de la revolución mundial y que ahora, al término del siglo XX, era la capital de la contrarrevolución mundial”.

Cuando poco después se sucedieron la caída del muro de Berlín y bajo su estremecedor impacto el colapso del "socialismo realmente existente", incluida la URSS, sectores de trabajadores aún revolucionarios socialistas del mundo quedaron más que desconcertados. Los dirigentes de los partidos de izquierda, en general, no dijeron y no han dicho algo significativo para explicar las particularidades de esta crisis. En una entrevista que al respecto le hizo la revista Quehacer, Quijano declaró que habiendo sido, entre muchos

20 En su discurso de orden, el 15 de marzo del 2009, Quijano desarrolló sus ideas sobre "la crisis del horizonte de sentido colonial/moderno/eurocentrado".

21 Organizada por la Escuela de Historia y la Facultad de Ciencias Sociales de San Marcos. 
otros, crítico permanente del "socialismo realmente existente", él no se iba a poner a llorar ante su derrumbe. Sus críticas siempre fueron a las direcciones ideológicas y políticas de esas experiencias que comprometieron la vida y las esperanzas de gran parte de la humanidad. En el Perú, los partidos y movimientos que se habían disputado entre sí la hegemonía de la dirección política de los trabajadores se desintegraron y quedaron en ruinas (Valladares, 2007).

$\mathrm{Al}$ ingresar a la última década del siglo XX, quedaba claro que después de dos siglos de luchas contra el capital y la burguesía dominantes, la humanidad asistía a la derrota mundial de la revolución y al triunfo mundial de la contrarrevolución. En este contexto, Aníbal Quijano sacó a relucir no solo su invariable y férrea voluntad de lucha, sino también una bien organizada arqueología del saber para producir nuevos conocimientos como armas contra el poder en tiempos de globalización y de emergencia de un nuevo horizonte de sentido histórico. 


\section{Bibliografía}

Alba Herrera, C. A. (2016). Influencia del pensamiento de José Carlos Mariátegui en Huarás-Áncash. Huaraz: Waraq Qoyllur.

Alba Herrera, C. A. (2000). Atusparia y la revolución campesina de 1885. Lima: Ediciones Inca.

Gutiérrez, M. (1988). La generación del 50: un mundo dividido. Lima: Ediciones Sétimo Ensayo.

Haya de la Torre, V. R. (1977). Por la emancipación de América Latina, artículos, mensajes y discurso (1923-1927). Obras completas (tomo 1). Lima: Editorial Juan Mejía Baca.

Mariátegui, J. C. (1991). Textos escogidos. Lima: Fondo de Cultura Económica.

Mariátegui, J. C. (1977). 7 ensayos de interpretación de la realidad peruana. Caracas: Editorial Biblioteca Ayacucho.

Mariátegui, J. C. (1976). Ideología y política. Amauta, 1926-1930 (edición facsimilar). Lima: Empresa Editora Amauta.

Molinari, T. (2017). Dictadura, cultura autoritaria y conflicto político en el Perú (19361939). Lima: Fondo Editorial de la Universidad Nacional Mayor de San Marcos.

Molinari, T. (2006). El fascismo en el Perú. La Unión Revolucionaria 1931-1936. Lima: Fondo Editorial de la Universidad Nacional Mayor de San Marcos.

Montoya Huamaní, S. (2018). La presencia del marxismo de Mariátegui en la obra de Aníbal Quijano. En Pacheco Chávez, H. (Coord.). Rompiendo la jaula de la dominación, ensayos en torno a la obra de Aníbal Quijano. Santiago de Chile: Editorial Doble Ciencia.

Ortega, J. y Gómez, Y. (2018). Mariátegui y los molinos de viento: el itinerario de Aníbal Quijano. En Pacheco Chávez, H. (Coord.). Rompiendo la jaula de la dominación, ensayos en torno a la obra de Aníbal Quijano. Santiago de Chile: Editorial Doble Ciencia.

Parker, G. y Chávez, A. (1976). Diccionario quechua: Áncash-Huaylas. Lima: Ministerio de Educación del Perú, Instituto de Estudios Peruanos.

Quijano, A. (2014). Cuestiones y horizontes: de la dependencia histórico estructural a la colonialidad/descolonialidad del poder. Selección y prólogo de Danilo Assis. Buenos Aires: CLACSO.

Quijano, A. (1974). Crisis imperialista y clase obrera en América Latina. Lima: Universidad de Texas.

Rochabrún, G. (Ed.). (2011). “He vivido en vano?”. La mesa redonda sobre Todas las sangres. Lima: Instituto de Estudios Peruanos. 
Torero, A. (1974). El quechua y la historia social andina. Lima: Universidad Ricardo Palma.

Valladares, M. (2013). El paro nacional del 19 de julio. Lima: Fondo Editorial de la Universidad Nacional Mayor de San Marcos, Pakarina Editores.

Valladares, M. (2011). Yungay en la memoria. Lima: Fondo Editorial de la Universidad Nacional Mayor de San Marcos, Pakarina Editores.

Valladares, M. (2007). Huelga policial y paro nacional de trabajadores en mayo de 1987. Detonantes de la más grave crisis política en el Perú de fines del siglo XX, Historias, 2.

Vargas Llosa, M. (1991). El pez en el agua. Madrid: Alfaguara.

Villanueva, V. (1975). El APRA en busca del poder. Lima: Editorial Horizonte.

Villanueva, V. (1973). La sublevación aprista de 1948. Tragedia de un pueblo y de un partido. Lima: Milla Batres.

Zubieta, F. (2019). Tras las huellas de Luis Pardo. Huacho: Killa Editorial. 